Histone $\mathrm{H1}^{\mathrm{O}}$ : its location in chromatin

\title{
B.J.Smith and E.W.Johns
}

Institute of Cancer Research, Fulham Road, London SW3 6JB, UK

Received 30 September 1980

\section{ABSTRACT}

Histone $\mathrm{H}^{\circ}$ is an $\mathrm{H} 5-1$ ike protein found in mammals. Its location in chromatin from animal tissues has been studied by micrococcal nuclease digestion and by quantification. It was found that $\mathrm{H} 1^{\circ}$ occurs in the linker region of chromatin, and replaces $\mathrm{Hl}$ there as it does so. As much as a third of the $\mathrm{Hl}$ becomes replaced, at least in some tissues. The abundance of $\mathrm{Hl}^{\circ}$ was similar in bulk chromatin and in a mononucleosome population which was putatively enriched in transcribed DNA sequences. It was concluded that $\mathrm{Hl}^{\circ}$ probably does not suppress transcription.

\section{INTRODUCTION}

Most, if not all eukaryotes possess histone $\mathrm{Hl}$. $\mathrm{Hl}$ is located on the linker region of chromatin, and has been implicated in the maintenance of compact conformations of chromatin, possibly by maintenance of linker DNA length (reviewed in refs 1 and 2). A protein similar to $\mathrm{Hl}$ in some respects, histone $\mathrm{H5}$, is also found in the linker region of chromatin, but only in nucleated erythrocytes. The function of $\mathrm{H} 5$ has been suggested as being one of suppression of transriptior: ${ }^{3}$ (reviewed in ref. 4). It is generally held that when $\mathrm{H} 5$ occurs it replaces $\mathrm{H}_{\mathrm{I}}$ (eg. refs 5 ana 6 ) but weintraub ${ }^{7}$ and 01 ins et $\mathrm{al}^{8}$ have suggested that $\mathrm{H} 5$ is present in addition to the normal $\mathrm{Hl}$ content (of approximately one $\mathrm{Hl}$ molecule per nucleosome).

A protein which is like $\mathrm{Hl}$ in overall amino acid content but which has some structural homology with avian $\mathrm{H} 5$, is $\mathrm{Hl}^{\circ}{ }^{9}$. The function of this protein has been suggested as being suppression of cell replication ${ }^{10}$ or of DNA synthesis ${ }^{11}$. By analogy with $\mathrm{HI}$ and $\mathrm{H} 5, \mathrm{H}^{\circ}$ may be expected to reside in the linker region of chromatin, perhaps replacing $\mathrm{Hl}$ when it does so. In the present work we test these expectations and investigate the association of $\mathrm{H}^{\circ}$ with the fraction of chromatin which is sensitive to brief digestion with micrococcal nuclease and which is reputed to be enriched in actively transcribing DNA sequences ${ }^{12,13}$. 
METHODS

\section{Preparation of nuclei and proteins}

For nuclease digestion studies, tissue from 2-6 week-old calves was used, for reasons of quantity, and because bovine $\mathrm{H}^{\circ}$ was available as a standard. The tissue used was brain, since it has minimal endogenous proteolytic and nucleolytic activities ${ }^{14,15}$. Brains were obtained from a local abattoir, transported on ice. For quantitative studies the species used was changed to the laboratory mouse (strain $\mathrm{CBA} / \mathrm{Ca}$ ) to ensure freshness of tissue and so a minimum of proteolysis. Mice were killed immediately before use.

Nuclei were prepared from fresh tissue in the presence of protease inhibitor phenylmethylsulphonyl fluoride as described previously ${ }^{16}$. Proteins were prepared by thorough extraction of nuclei four times with HC1 $(0.25 \mathrm{M})$ and by precipitation by addition of acetone (10 vol).

\section{Digestion with nuclease}

Freshly-prepared nuclei were suspended to 6-8 $\mathrm{mg}$ nucleic acid/ml in sucrose (0.3M), $\mathrm{CaCl}_{2}(1 \mathrm{mM})$, tris $(5 \mathrm{mM})$ and cacodylic acid (to $\mathrm{pH} 7.3$ ), and warmed to $37^{\circ} \mathrm{C}$. Micrococcal nuclease (Worthington) was added to a concentration of 50 units/mg nucleic acid. In the case of controls, buffer was added instead of enzyme. Incubation at $37^{\circ}$ continued for $90 \mathrm{sec}$ and then the reaction was stopped and nuclei lysed by cooling on ice, addition of diaminoethanetetraacetic acid (EDTA, to $1.5 \mathrm{mM}$ ) and brief homogenization. Suspensions were then centrifuged $\left(90,000 \times \mathrm{g}, 4^{\circ} \mathrm{C}, 30 \mathrm{~min}\right)$ to yield a supernatant which was suitable for electrophoresis, after dialysis (overnight, $4^{\circ} \mathrm{C}$, against triethano1amine (2mM) EDTA (2mM) glycerol (10\% v/v) and phenylmethylsulphonyl fluoride $(0.5 \mathrm{mM})$. The amounts of perchloric acid ( $5 \% \mathrm{w} / \mathrm{v})$-soluble nucleotides in suspensions of nuclei before and after treatment were estimated by absorbance at wavelength $260 \mathrm{~nm}$. It was found that the treatment with micrococcal nuclease rendered approximately $1.5-3.0 \%$ of nucleic acids soluble in perchloric acid.

\section{Electrophoresis}

Deoxyribonucleoprotein particles were fractionated in "DNP" gels, of $5 \%$ acrylamide ${ }^{17}$, in slabs of $0.3 \times 12 \times 12 \mathrm{~cm}$. Electrophoresis (at a constant voltage of $150 \mathrm{~V}$ ) was continued with cooling until 30 min after the bromophenol blue dye front had emerged from the gel.

Proteins were analysed in "SDS" gels of $15 \%$ acrylamide and sodium dodecy1sulphate $(0.1 \%)^{18}$, in $0.1 \times 12 \times 12 \mathrm{~cm}$ slabs. Electrophoresis (at a constant current of $20 \mathrm{~mA}$ ) was continued with cooling until the bromophenol blue dye front reached the bottom of the gel.

DNA was analysed by electrophoresis in "DNA" gels of $4 \%$ acrylamide and 
sodium dodecylsulphate $(0.1 \%)^{19}$ in $0.3 \times 12 \times 12 \mathrm{~cm}$ slabs. Electrophoresis was continued at room temperature at a constant voltage of $20 \mathrm{~V}$, until the bromophenol blue dye front had neared the bottom of the gel.

Two-dimensional gels were of two types: (a) DNP gel in the first dimension, SDS gel in the second; (b) DNP gel in the first dimension, DNA gel in the second. Strips from the first gel (DNP) were equilibrated in appropriate buffers before application to the top of the second gel.

Double stranded nucleic acid was stained with ethidium bromide after washing the gel with methanol/water $(50 / 50, \mathrm{v} / \mathrm{v})^{19}$ and visualized by irradiation with ultraviolet light. Proteins were visualized routinely by staining with Coomassie Brilliant Blue R250 ${ }^{16}$. However, we have found that this strain is unsatisfactory for quantitative staining of protein - it does not bind to the protein quantitatively, it varies in its ability to stain from batch to batch, and it exhibits metachromicity. Procion Navy MXRB (I.C.I. Ltd.) suffers none of these drawbacks, although being perhaps two or threefold less sensitive 20 . Thus, Procion Navy was used to quantitatively stain both one- and two-dimensional gels. Core histones and $\mathrm{Hl}$ were previously shown to be quantitatively stained ${ }^{20}$, as is $\mathrm{Hl}^{\circ}$ (data not shown). However, the amount of stain taken up by $\mathrm{Hl}^{\circ}$ is slightly less (approximately 80\%) than that by homologous $\mathrm{H} 1$, on a weight basis. One-dimensional gels stained with Procion Navy were scanned at $580 \mathrm{~nm}$ as described previous $1 \mathrm{y}^{20}$, and two-dimensional gels were cut into narrow strips which were each scanned in the same way. Proteins in two-dimensional gels were quantified by summing appropriate peaks in the various scans.

Standard methods of statistical analysis were employed where appropriate.

\section{RESULTS}

The location of $\mathrm{Hl}^{\circ}$ in chromatin

Digestion of calf brain nuclei with micrococcal nuclease yielded monomer and oligomer nucleosome fractions, but in control experiments there was no generation of nucleosomes, in agreement with the previously observed lack of endogenous nuclease in brain ${ }^{14,15}$. Small amounts of some protein species were found in supernatant fractions in control experiments, presumably of ribonucleoprotein particle origin. These proteins had lesser mobilities than that of $\mathrm{Hl}$ in SDS gels, and so did not interfere with analysis of the proteins of interest from the various nucleosomal species. This was done by twodimensional electrophoresis (DNP-SDS), in which $\mathrm{Hl}$ and $\mathrm{Hl}^{\circ}$ were identified by co-electrophoresis of standard proteins. 
Nucleic Acids Research

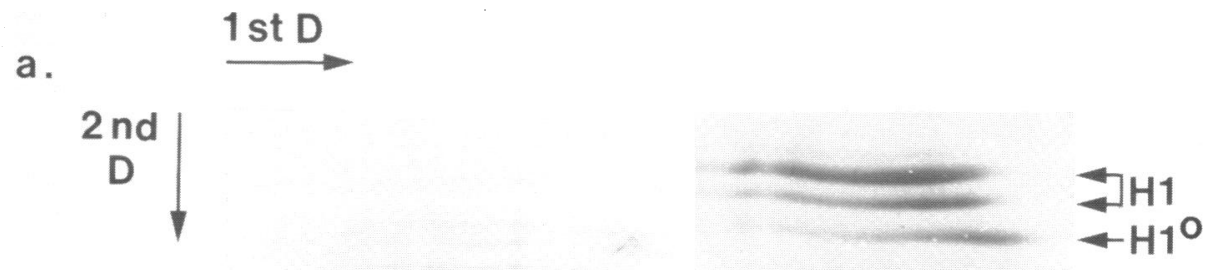

b.

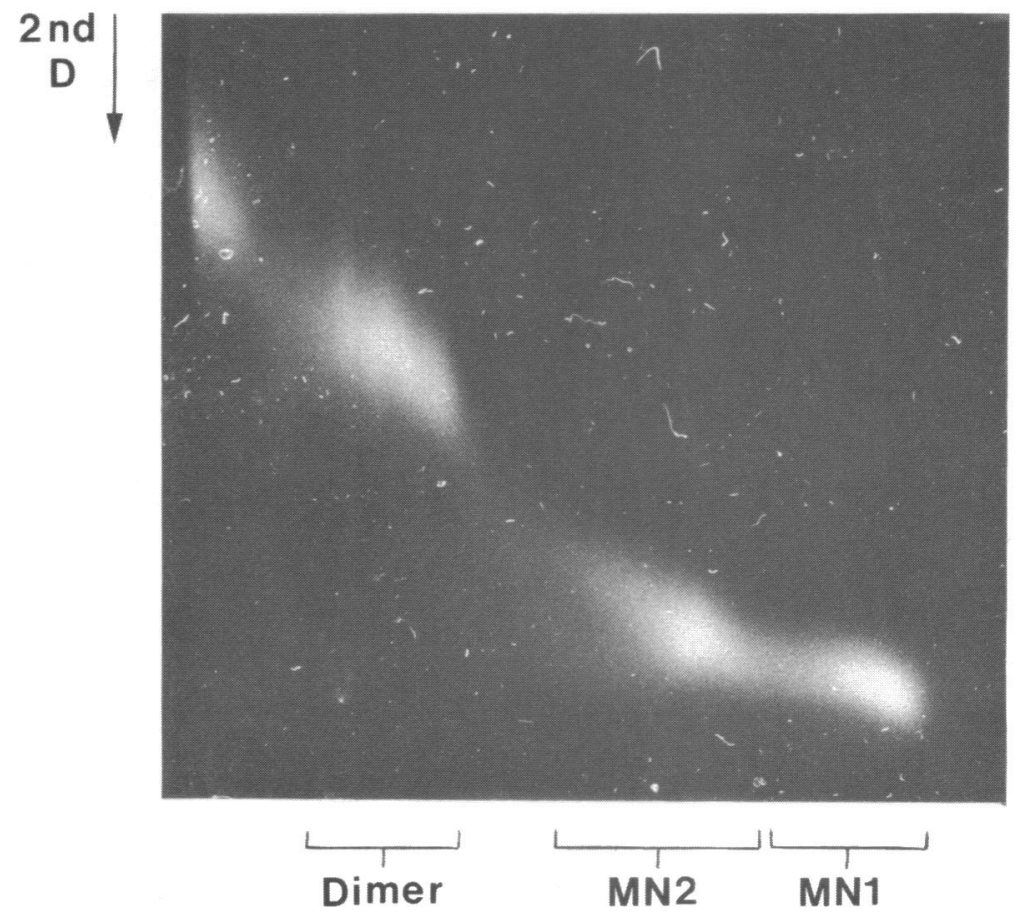


Fig. la shows that 1 ike $\mathrm{H} 1, \mathrm{H}^{\circ}$ was present in those fractions which retain linker DNA (mononucleosome type $\mathbb{M N}^{21}$, and larger particles) but not in the linker-less core particle $\left(" \mathrm{MN} 1^{21}\right)$. This suggests that $\mathrm{Hl}^{\circ}$ resides on the linker region of chromatin.

Inspection of $\mathrm{H} 1$ and $\mathrm{H}^{\circ}$ bands in the MN2 region shows that they are not exactly coincident (see fig. la, and inset). This indicates that there exist particles (here called $\mathrm{MN}^{\circ}$ ) which bear $\mathrm{H}^{\circ}$ but not $\mathrm{Hl}$, and suggests that $\mathrm{H}^{\circ}$ can replace $\mathrm{H} l$ in chromatin.

Analysis of the DNA in the digested calf brain chromatin fractions (fig. 1b) did not reveal any diversity of DNA lengths which may have corresponded to the diversity of MN2 types. However, it may be beyond this technique to resolve very small differences in DNA lengths.

Quantification of $\mathrm{Hl}$ and $\mathrm{H}^{\circ}$ in various chromatin fractions

Calf brain nuclei were digested to $1.5-3.0 \%$ acid-soluble nucleotides by micrococcal nuclease. The amounts of $\mathrm{Hl}^{\circ}$ and $\mathrm{Hl}$ (relative to core histones) in MN2 and dimer fractions were determined from quantitatively-stained two-dimensional electrophoretograms (DNP-SDS). These gets are slightly less able than are one-dimensional gels to resolve protein bands which run close together, so results of quantification are slightly less accurate than those from one-dimensional gels. The MN2 and dimer fractions contained approximately the same amounts of core histones. Table 1 gives the results together with similar quantifications (from one-dimensional gels) of two preparations from undigested calf brain nuclei (which were insignificantly different from each other at the $5 \%$ leve1, with respect to histone/histone ratios). Both MN2 and dimer fractions seemed to be slightly depleted in $\mathrm{Hl}$ and perhaps slightly enriched in $\mathrm{H}^{\circ}$. The ratio $\left(\mathrm{Hl}+\mathrm{H}^{\circ}\right)$ /core histones was less than that in whole chromatin. This may have been due to replacement of Hl-containing nucleosomes by nucleosomes bearing non-histone(s), although no such protein was obvious on our gels. The increase in ratio $\mathrm{H}^{\circ} / \mathrm{Hl}$, probably mainly due to loss of $\mathrm{Hl}$, is analogous to the increased $\mathrm{H} 5 / \mathrm{H} 1$ ratio in oligonucleosomes (compared with that in whole chromatin), which are produced by digestion of chicken erythrocyte chromatin by micrococcal nuclease 22 .

Fig. 1 .

Two dimensional electrophoretograms of micrococcal nuclease-digested calf brain nuclei: (a) DNP-SDS electrophoresis, gel stained with Procion Navy. Inset: enlarged portion (of MN2 region bearing $\mathrm{HI}$ and $\mathrm{Hl}^{\circ}$ ) from a sister gel stained with Coomassie Brilliant Blue R250; (b) DNP-DNA electrophoresis, gel stained with ethidium bromide. 
Table 1: Quantification of $\mathrm{Hl}$ and $\mathrm{H}^{\circ}$ in various calf brain chromatin fractions: histone/histone ratios determined from electrophoretograms stained by Procion Navy

\begin{tabular}{|c|c|c|c|c|c|}
\hline $\begin{array}{l}\text { Chromatin } \\
\text { fraction }\end{array}$ & $\begin{array}{c}\mathrm{n} \text {, no. of } \\
\text { samples } \\
\star\end{array}$ & $\begin{array}{l}\text { Ratios: Mean } \\
\mathrm{Hl} / \mathrm{CH}^{\dagger}\end{array}$ & $\begin{array}{l}\text { (standard devi } \\
\mathrm{H} 10 / \mathrm{CH}\end{array}$ & $\begin{array}{c}\text { iation }), 2 \text { sig. } \\
\left(\mathrm{H} 1+\mathrm{H} 1{ }^{\circ}\right) / \mathrm{CH}\end{array}$ & $\begin{array}{l}\text { fig. } \\
\mathrm{H} 1^{\circ} / \mathrm{HI}\end{array}$ \\
\hline$M \mathbb{M} 2$ & 2 & $0.14(0.049)$ & $0.040(0.00028)$ & $0.18(0.0049)$ & $0.30(0.11)$ \\
\hline Dimer & 2 & $0.14(0.0050)$ & $0.044(0.031)$ & $0.18(0.024)$ & $0.33(0.25)$ \\
\hline Whole (a) & 16 & $0.20(0.047)$ & $0.033(0.014)$ & $0.23(0.055)$ & $0.16(0.060)$ \\
\hline Whole (b) & 14 & $0.23(0.049)$ & $0.029(0.0077)$ & $0.26(0.047)$ & $0.14(0.062)$ \\
\hline
\end{tabular}

*: each sample itself an average of two or more scans.

$+: \mathrm{CH}=$ core histone

(a), (b) = two separate preparations, insignificantly different (at $5 \%$ level)

The results indicate that there is neither a great increase nor a decrease in $\mathrm{Hl}^{\circ}$ (relative to core histones) in these monomer and dimer fractions. Quantification of $\mathrm{H} 1$ and $\mathrm{H} 1$ in various animal tissues

The species used for this purpose was mouse. That the protein of interest in this species was in fact $\mathrm{H}^{\circ}$ was confirmed by the following:

(a) it was soluble in $\mathrm{HCl}(0.25 \mathrm{M})$ and perchloric acid ( $5 \% \mathrm{w} / \mathrm{v})$, as is bovine $\mathrm{Hl}^{\circ}{ }^{16}$;

(b) its mobility in SDS electrophoresis was identical to that of bovine $\mathrm{H}^{\circ}$;

(c) its cleavage by cyanogen bromide generated a major peptide of identical electrophoretic mobility, in SDS gels, to the corresponding peptide from bovine $\mathrm{Hl}^{\mathrm{O}}$ (see ref.16);

(d) its tissue distribution was as expected for $\mathrm{H}^{\circ}$ - less in tissues which are more active in DNA synthesis (see ref 10 and table 2);

(e) its behaviour was as expected for $\mathrm{H}^{\circ}$ (by analogy with regenerating $\operatorname{liver}^{23}$ and pancreas ${ }^{11}$ ) when mouse salivary gland cells were stimulated to enter the cell cycle by administration of isoproteneno $1^{24}-$ levels of the putative $\mathrm{Hl}^{\circ}$ were lower in dividing cells than in cells which were unstimulated and in $G_{0}$ phase (data not shown). 
The thymus gland has little or no $\mathrm{Hl}^{\circ}$ (less than $0.5 \%$ relative to $\mathrm{Hl}$ in calf thymus (Smith and Johns, unpubl.)), and the amount of $\mathrm{Hl}$ in mouse thymus has been estimated to be one molecule of $\mathrm{Hl}$ per nucleosome ${ }^{20}$. Therefore, the HI level in the thymus was taken as the maximum, and $\mathrm{Hl}$ and $\mathrm{H}^{\circ}$ levels in other mouse organs compared with it. To enable identical treatment of all tissues studied, young mice (4-7 weeks old) were used, for the thymus atrophies with age. To facilitate scanning of protein bands on stained gels, preparations free of cytoplasmic proteins were made, from nuclei. Preparation of nuclei seems to result in some degradation or other alteration of $\mathrm{Hl}^{\circ} 16$, but since the product of alteration is all or virtually all of the molecule and it has a mobility in SDS gels which is almost identical with that of the parent molecule, no correction was made for this. No loss of $\mathrm{Hl}$ was apparent during isolation of nuclei.

Various histone/histone ratios were determined for young mouse tissues, from scans of replicated, quantitatively-stained, one-dimensional SDS gels. The results are summarised in table 2 . The ratio $\mathrm{Hl} /$ core histone in each of the liver and kidney was significantly lower (at the $5 \%$ level) than that of the thymus, but in each case the ratio $\left(\mathrm{H} 1+\mathrm{H} 1^{\circ}\right) /$ core histone was not significantly different. This suggests that in organs where $\mathrm{H}^{\circ}$ occurs, it replaces $\mathrm{Hl}$, so that the level of total lysine-rich histone $\left(\mathrm{Hl}+\mathrm{H} 1^{\circ}\right)$ remains constant at about one molecule of $\mathrm{Hl}$ or $\mathrm{H}^{\circ}$ per nucleosome.

It has been reported that $\mathrm{Hl}^{\circ}$ levels increase with age ${ }^{25,26}$. Preparations were made from nuclei of tissues from 6 and 9 month-old mice. Quantification of histones in these preparations (Table 2) agrees with this observation, with $\mathrm{H}^{\circ}$ levels increasing and stabilizing by 6 months of age. The results from aged mice support the conclusion from more comprehensive data with young animals - that $\mathrm{H}^{\circ}$ replaces $\mathrm{H} 1$.

Upon SDS gel electrophoresis, the $\mathrm{Hl}$ split into two bands, the relative abundance of which changed from tissue to tissue. However, no firm conclusion could be drawn concerning the preferential replacement of one $\mathrm{Hl}$ band or the other by $\mathrm{H}^{\circ}$ during ageing. Thus, it remains unknown which $\mathrm{Hl}$ subfraction(s) becomes replaced by $\mathrm{H}^{\circ}$.

\section{DISCUSSION}

The evidence presented here shows that $\mathrm{H}^{\circ}$ can replace $\mathrm{Hl}$ in its position in the linker region, and probably protect a length of DNA not very, if at all different from that protected by $\mathrm{Hl}$ (about 20 base-pairs) 27 . The replacement of $\mathrm{Hl}$ can be quite extensive, so that for old mouse liver 
Table 2: Quantification of $\mathrm{Hl}$ and $\mathrm{H}^{\circ}$ in nuclei from various mouse tissues: histone/histone ratios determined from electrophoretograms stained by Procion Navy

\begin{tabular}{|c|c|c|c|c|c|c|c|}
\hline Tissue & $\begin{array}{c}\text { Age } \\
\text { (mths) }\end{array}$ & $\begin{array}{l}\text { No. of } \\
\text { preps. }\end{array}$ & $\begin{array}{c}\mathrm{n}, \text { total } \\
\text { no. of } \\
\text { samples } \\
\star\end{array}$ & $\begin{array}{l}\text { Ratios:M } \\
\mathrm{H} 1 / \mathrm{CH}^{\dagger}\end{array}$ & ean $\begin{array}{c}\text { (standard } \\
\mathrm{H} 1 \% / \mathrm{CH}\end{array}$ & $\begin{array}{r}\text { deviation) }, 2 \mathrm{~s} \\
\left(\mathrm{H} l+\mathrm{H} 1^{\circ}\right) / \mathrm{CH}\end{array}$ & ig. fig. \\
\hline Thymus & $1-2$ & 3 & 19 & $0.28(0.053)$ & - & - & - \\
\hline Liver & $1-2$ & 4 & 19 & $0.21(0.058)$ & $0.055(0.018)$ & $0.26(0.070)$ & $0.26(0.034) \neq$ \\
\hline Kidney & $1-2$ & 2 & 13 & $0.21(0.063)$ & $0.073(0.035)$ & $0.28(0.096)$ & $0.31(0.077)^{x}$ \\
\hline Thymus & 6 & 1 & 3 & $0.28(0.0076)$ & - & - & - \\
\hline Liver & 6 & 1 & 3 & $0.20(0.0083)$ & $0.090(0.0048)$ & $0.29(0.013)$ & $0.45(0.013)$ \\
\hline Kidney & 6 & 1 & 3 & $0.17(0.011)$ & $0.071(0.0095)$ & $0.24(0.022)$ & $0.42(0.040)$ \\
\hline Liver ${ }^{+}$ & 9 & 1 & 3 & $0.20(0.032)$ & $0.082(0.015)$ & $0.28(0.047)$ & $0.41(0.012)$ \\
\hline Kidney & 9 & 1 & 2 & $0.21(0.028)$ & $0.097(0.016)$ & $0.31(0.044)$ & $0.46(0.015)$ \\
\hline
\end{tabular}

*: each sample itself an average of two or more scans.

$+: \mathrm{CH}=$ core histones

†: $\mathrm{n}=25$

$\mathrm{x}: \mathrm{n}=16$

+: 9 mth.-old thymus not done - insufficient tissue in old mice.

or kidney it was estimated that on stained gels $\mathrm{H} 1^{\circ} / \mathrm{H} 1 \simeq 0.4$. Bovine $\mathrm{H} 1^{\circ}$ takes up slightly less stain than does bovine H1 (see Methods). Assuming that this is also the case in mouse, and correcting accordingly, on a weight basis $\mathrm{H} 1^{\circ} / \mathrm{H} 1 \simeq 0.5$, which is equivalent to about a third of nucleosomes bearing $\mathrm{H}^{\circ}$ instead of $\mathrm{Hl}$.

The difference in mobilities of $\mathbb{M N} 2$ and $\mathbb{M N} 2^{\circ}$ particles in DNP gels is of interest. This is analogous to H5-containing mononucleosomes ("MN2E") moving faster than $\mathrm{Hl}$-containing MN2 particles in DNP gels ${ }^{22}$. This could have arisen by MN2E being more negatively charged, because its DNA was 5 to 10 base pairs longer than that in $\mathrm{MN}^{22}$, although Simpson ${ }^{27}$ apparently found no difference in DNA lengths between such particles. The nature of the difference between MN2 and $\mathrm{MN}^{\circ}$ is unclear. There may be a difference in DNA lengths but it must be small if it exists. $\mathrm{H} 1$ and $\mathrm{H}^{\circ}$ contain roughly similar proportions of acidic and basic amino acid residues ${ }^{16}$, and the isoelectric point of $\mathrm{H}^{\circ}{ }^{\circ}$ is probably slightly higher than that of $\mathrm{H}^{28}$, so differences in charge probably 
do not explain the difference in mobilities of MN2 and MN2 ${ }^{\circ}$. The explanation possibly lies in the sizes of the particles, arising perhaps by differences in compaction, but also by differences in molecular weight $-\mathrm{Hl}^{\circ}$ probably has a smaller molecular weight than $\mathrm{H} 1$ does. This is suggested by the greater mobility of $\mathrm{Hl}^{\circ}$ in SDS gels ${ }^{16}$, and its lesser mobility upon gel filtration chromatography ${ }^{29}$.

The high $\mathrm{H} 5 / \mathrm{Hl}$ ratio observed in oligonucleosomes from micrococcal nuclease digested chicken erythrocyte chromatin ${ }^{22}$, is analogous to our result with high $\mathrm{H} 1 \% / \mathrm{H} 1$ ratios in monomer and dimer fractions. Bakeyeva and Bakayev ${ }^{22}$

suggested that this arose because $\mathrm{H} 5$ protected nucleosomes against nuclease attack more efficiently than $\mathrm{Hl}$ did (that is, providing greater resistance to further nuclease action which generates $\mathbb{M N l}$ particles). Like $\mathrm{H} 5, \mathrm{Hl}^{\circ}$ may protect against nuclease attack more efficiently than $\mathrm{Hl}$ does.

While this paper was in preparation, two relevant papers appeared in print. The first, by $D^{\prime}$ Anna et al ${ }^{30}$ reported (contrary to our results from normal tissues) that an $\mathrm{H}^{\circ}$-like protein accumulated without concomitant loss of $\mathrm{Hl}$ in cultured cells blocked in Gl phase by butyrate treatment. It is known, however, that blockage of the cell cycle disrupts the cell's normal functioning and may introduce artifacts (e.g. refs. 31,32). That this may have been the case was suggested by the fact that there was no direct correspondence between the abundance of this protein and the proportion of the population blocked in $\mathrm{Gl}^{30}$.

The second relevant paper by Albright et al ${ }^{33}$ mentions that "NF" (probably $\mathrm{H} 1^{\circ}$ ) occurs in MN2-type mononucleosomes, agreeing with our observations, as does the report of "IP 25 " (possibly an $\mathrm{H}^{\circ}{ }^{\circ}$-like protein described in mouse erythroleukaemia cells) existing in the linker region ${ }^{34}$.

It has been found that brief digestion of chromatin by micrococcal nuclease generates a mononucleosome population enriched in transcribed sequences 12,13 . The brain is an organ which is active in transcription ${ }^{35}$, so it is assumed that in the present work brief digestion yielded a mononucleosome fraction enriched in transcribed sequences. It has also been reported that micrococcal nuclease may preferentially attack nascent DNA ${ }^{36}$, but although brains from young animals such as those used here synthesize some $\mathrm{DNA}^{37}$, we expect the contribution from this source to be small. Since it was found that $\mathrm{Hl}^{\circ}$ was only slightly or not at all enriched in MN2 and dimer fractions, we tentatively conclude that the distribution of $\mathrm{H}^{\circ}$ is not affected by transcription. This conclusion is in apparent disagreement with a pair of (contradictory) reports. Firstly, the $\mathrm{Hl}^{\circ}$-like protein $\mathrm{IP}_{25}$ was found not to be 
solubilized by digestion by DNAse I, which lead to the suggestion that this protein is associated with repression of gene activity ${ }^{34}$. Secondly, and to the contrary, it was reported 38 that a protein ("20K") with electrophoretic mobilities like those of $\mathrm{H}^{\circ}$ was enriched in putative actively transcribing chromatin as isolated by the DNAse $\mathrm{II} / \mathrm{Mg}^{2+}$ solubility procedure from trout testis (an organ which in mammals contains $\mathrm{Hl}^{\circ}$ ). Our conclusion is possibly supported by the observation that there is in rat satellite chromatin a putative $\mathrm{H} 1^{\circ}$ protein which is present in quantities not very or at all different from those of bulk chromatin 39,40 . Satellite chromatin is generally considered to be transcriptionally inactive, although there is one report to the contrary ${ }^{41}$.

Our results disfavour the idea of analogy with the structurally-related $\mathrm{H} 5$ that $\mathrm{Hl}^{\circ}$ may repress transcription, but probably still allow that it may repress DNA synthesis.

\section{ACKNOWLEDGEMENTS}

We would like to thank Dr. G. Goodwin and our other colleagues for helpful discussion, Ms C. Toogood for able technical assistance and Mr.K. Gomer for injection of mice with isoproterenol. This work was supported by MRC grant G976/120.

\section{REFERENCES}

1. Walker, J.M., Goodwin, G.H., Smith, B.J. and Johns, E.W. (in press) in Comprehensive Biochemistry, Florkin, M. and Stotz, E.H., Eds., E1sevier North Holland, Amsterdam.

2. McGhee, J.D. and Felsenfeld, G. (1980) Ann.Rev.Biochem. 49, 1115-1156.

3. Bradbury, E.M., Crane-Robinson, C. and Johns, E.W. (1972) Nature New Biol. $238,262-264$.

4. Elgin, S.C.R. and Weintraub, H. (1975) Ann.Rev.Biochem. 44, 725-774.

5. Dick, C. and Johns, E.W. (1969) Biochim. Biophys.Acta 175, 414-418.

6. Miki, B.L.A. and Neelin, J.M. (1980) Nucleic Acids Res. 8, 529-542.

7. Weintraub, H. (1978) Nucleic Acids Res. 5, 1179-1188.

8. Olins, A.L., Breillat, J.P., Carlson, R.D., Senior, M.B., Wright, E.B. and O1ins, D.E. (1977) in The Molecular Biology of the Mammalian Genetic Apparatus, T'so, P., Ed., pp.211-237, Elsevier North-Holland Biomedical Press.

9. Smith, B.J., Walker, J.M. and Johns, E.W. (1980) FEBS Lett. 112, 42-44.

10. Panyim, S. and Chalkley, R. (1969) Biochemistry 8, 3972-3979.

11. Marsh, W.H. and Fitzgerald, P.J. (1973) Fed.Proc. 32, 2119-2125.

12. Bloom, K.S. and Anderson, J.N. (1978) Ce11, 15, 141-150.

13. Levy-Wilson, B. and Dixon, G.H. (1979) Proc.Nat1.Acad.Sci.USA, 76, 16821686 .

14. Balhorn, R., Weston, S., Mazrimas, J.A. and Young, T. (1978) J.Cel1 Biol. 79, CH669.

15. Myulberg, A.A., Tishchenko, L.I., Karyagina, I.Y. and Grigorjeva, M.B. (1978) Biokhimia 43, 340-349.

16. Smith, B.J. and Johns, E.W. (1980) FEBS Lett. 110, 25-29. 
17. Bakayev, V.V., Bakayeva, T.G. and Varshavsky, A.J. (1977) Ce11 11, 619-629.

18. Laemli, U.K. (1970) Nature (Lond.) 227, 680-685.

19. Todd, R.D. and Garrard, W.T. (1977) J.Biol.Chem. 252, 4729-4238.

20. Smith, B.J., Toogood, C.I.A. and Johns, E.W. (in press) J.Chromatog.

21. Varshavsky, A.J., Bakayev, V.V., Nedospasov, S.A. and Georgiev, G.P. (1977) Cold Spring Harb.Symp.Quant.Biol. 42, 457-473.

22. Bakayeva, T.G. and Bakayev, V.V. (1978) Molec.Biol.Rep. 4, 185-189.

23. Balhorn, R., Chalkley, R. and Granner, D. (1972) Biochemistry 11, $1094-1098$.

24. Baserga, R. (1966) Life Sci. 5, 2033-2039.

25. Medvedev, Z.A., Medvedeva, M.N. and Huschtscha, L.I. (1977) Gerontology $23,334-341$.

26. Varrichio, F. (1977) Arch.Biochem.Biophys. 179, 715-717.

27. Simpson, R.T. (1978) Biochemistry 17, 5524-5531.

28. Valkonen, K.H. and Piha, R.S. (1980)'Analyt.Biochem. 104, 499-505

29. Pehrson, J. and Cole, R.D. (1980) Nature (Lond.) 285, 43-44.

30. D'Anna, J.A., Tobey, R.A. and Gurley, L.R. (1980) Biochemistry 19, 26562671 .

31. Nadeau, P., Oliver, D.R. and Chalkley, R. (1978) Biochemistry 17, 48854893.

32. Detke, S., Lichtler, A., Phillips, I., Stein, J. and Stein, G. (1979) Proc.Nat1.Acad.Sci.USA 76, 4995-4999.

33. Albright, S.C., Wiseman, J.M., Lange, R.A. and Garrard, W.T. (1980) J.Bio1.Chem. 255, 3673-3684.

34. Keppe1, F., Allet, B., and Eisen, H. (1979) Eur.J.Biochem. 96, 477-482.

35. Chikaraishi, D.M., Deeb, S. and Sneoka, N. (1978) Cel1 13, 111-120.

36. Hildebrand, C.E. and Walters, R.A. (1976) Biochem.Biophys.Res.Commun. $73,157-163$.

37. Kuenzle, C.C., Bregnard, A., Hubscher, U. and Ruch, F. (1978) Exp.Ce11 Res. 113, 151-160.

38. Davie, J.R. and Candido, E.P.M. (1978) Proc.Nat1.Acad.Sci.USA 75, 35743577 .

39. Mazrimas, J.A., Balhorn, R. and Hatch, F.T. (1979) Nucleic Acids Res. 7, 935-946.

40. Mathew, C.G.P. (1980) PhD Thesis, London Univ.

41. Varley, J.M., Macgregor, H.C. and Erba, H.P. (1980) Nature(Lond.) 283, 686-688. 